\title{
Study of prevalence of lymphoceles after kidney transplantation
}

\author{
Afshar Zomorodi ${ }^{\mathbb{D}}$, Farnood Salmani Milani², Mohsen Mohammad Rahimi ${ }^{{ }^{*}(\mathbb{D})}$ \\ ${ }^{1}$ Kidney Research Center, Tabriz University of Medical Sciences, Tabriz, Iran \\ ${ }^{2}$ Faculty of Medicine, Tabriz University of Medical Sciences, Tabriz, Iran
}

\section{Correspondence to:}

Mohsen Mohammad Rahimi,

Email: mm.rahimi1357@gmail. com

Received: 19 June 2021 Accepted: 7 Aug. 2021 ePublished: 20 Aug. 2021

Keywords: Lymphocele, Kidney transplantation, End-stage renal disease

\begin{abstract}
Introduction: One of the complications of renal transplantation after surgery, which is frequently observed, is the symptomatic accumulation of fluid around the kidney, such as hematoma, lymphocele or lymphuria. Objectives: The incidence of lymphocele after kidney transplantation is widely different, therefore we decided to conduct a study to investigate the prevalence of lymphocytes in transplant recipients. Patients and Methods: The present study was a cross-sectional descriptive-analytical study. The target population in this study was adult and middle-aged men and women with end-stage renal disease (ESRD) who have undergone kidney transplant surgery at the kidney center of Imam Reza hospital in the last 5 years. Results: In all transplant recipients, symptomatic lymphoceles were observed in only 5 patients ( 3 female and 2 male patients with the mean age of $40.2 \pm 17.2$ years) who occurred on average $48.4 \pm 21.12$ days after surgery between 24 days and 78 days. The results showed that $62 \%$ (156 cases) of patients were men and 211 patients $(84.4 \%)$ were male transplant recipients. Also, 198 (79.2\%) transplant donors were living donor and $52(20.8 \%)$ were deceased donor/brain death.

Conclusion: In the present study, we found the prevalence of lymphocele in transplant recipients in the kidney transplant center of Imam Reza in five years is 5 patients $(2 \%)$ out of 250 patients with an average annual incidence of $1-2 \%$.
\end{abstract}

\section{Introduction}

For patients with end-stage renal disease (ESRD), the current treatment is a kidney transplant. The most common complications of this method are lymphocele, hematoma and urinoma $(1,2)$. The clinical problem of lymphocele after kidney transplantation remains unresolved. By definition, lymphocele are the accumulation of lymph fluid around the transplanted kidney, which usually occurs 2 to 6 months after transplantation $(3,4)$. Some lymphocele may be asymptomatic for a long time $(5,6)$. Lymphocele appear to be the result of lymph leakage and poor wound healing (6). Although the exact source of lymphatic fluid is not known, both the recipient and donor lymphatic systems are involved (7). In various studies, the incidence of lymphocele has been reported between 5 to $40 \%$ (8). This large variation may be due to a lack of routine postoperative follow-up and prospective data collection. In most cases, lymphoceles are asymptomatic and are diagnosed on routine ultrasound examinations (9-11). Symptoms occur when lymphoceles put pressure on nearby structures. The nature of these symptoms depends on the location

\section{Key point}

The prevalence of lymphocele in transplant recipients is rare with an average annual incidence of $1-2 \%$.

of lymphoceles, which are divided into three categories: urological, vascular, and visceral. Pressure on the urinary system can increase creatinine levels, dysuria, urinary retention and obstruction of urine flow. In addition, it may cause transplant rejection by impairing kidney function $(12,13)$. Symptoms associated with lymphocele include renal dysfunction, unilateral leg edema, hypertension, pain, fever, urinary tract obstruction, ipsilateral venous thrombosis, and palpable mass (14-17). Diagnosis of lymphocele after kidney transplantation is initially based on clinical examination and ultrasound imaging $(18,19)$. Ultrasound is the choice method for detecting fluid accumulation in the pelvic area $(20,21)$. If ultrasound is not sufficient for diagnosis, lymphocytes can usually be detected by CT scan or MRI without the use of contrast (21). The most common treatments are aspiration, external drainage, sclerotherapy, and open or

Copyright $\odot 2021$ The Author(s); Published by Society of Diabetic Nephropathy Prevention. This is an open-access article distributed under the terms of the Creative Commons Attribution License (http://creativecommons.org/licenses/by/4.0), which permits unrestricted use, distribution, and reproduction in any medium, provided the original work is properly cited. 
laparoscopic surgery $(22,23)$. Symptomatic lymphoceles need drainage to reduce symptoms. Drainage can be performed as percutaneous with or without sclerosing agent or through open surgery (7-9).

\section{Objectives}

The aim of this study was to analyze the prevalence of lymphocele in the kidney center of Imam Reza hospital in order to understand the time of symptom emergence and effectiveness of treatment and prevent unwanted complications.

\section{Patients and Methods Study design}

This was a cross-sectional descriptive-analytical study of patients with ESRD who underwent kidney transplant surgery at the kidney center of Imam Reza hospital in the last 5 years. Inclusion criteria were having a transplanted kidney (from a living donor or cadaver) that has undergone surgery in Imam Reza hospital in Tabriz during the last 5 years and consent to cooperate in the study. Exclusion criteria were postoperative haematomas, intraoperative urinomas, postoperative abscesses, and dissatisfaction with the study and incomplete patient record. Since the onset of lymphocele usually occurs in the first six months after surgery, patients would be followed up for at least six months. In this study, all data such as age, gender, time of lymphocele onset, selective lymphocele treatment, lymphocele recurrence, and symptoms were obtained from the records of patients who underwent kidney transplant surgery in the last 5 years (2015-2020).

\section{Statistical analysis}

Data analysis was performed using SPSS version 26. After Kolmogorov-Smirnov test and ensuring the normal distribution of variables, the relationship between individual characteristics (age, education, occupation) was recorded in a questionnaire using chi-square, independent t-test and ANOVA test. $P$ value less than 0.05 was considered significant. Data were also reported as descriptive statistics (frequency and percentage) and mean $\pm \mathrm{SD}$.

\section{Results}

In this study, in general, during five years (May 2015 to August 2020), about 250 patients with ESRD diagnosis underwent kidney transplant surgery at Imam Reza hospital in Tabriz. The files of these patients were reviewed retrospectively. In these patients, retroperitoneal transplanted kidney and perfusion with iliac vein and iliac artery to the bladder were used for transplantation. Additionally, 62\% (156 cases) of patients were men; 211 patients $(84.4 \%)$ were male transplant recipients and 39 patients (15.6\%) were female; 198 patients $(79.2 \%)$ of the transplant donors were living donors and 52 patients (20.8\%) were brain death/deceased donor. The mean age of transplant recipients was $40.61 \pm 14.23$ years with a minimum age of 8 years and a maximum of 69 years therefore, only 5 patients (2\%) had a family relationship with the donor; 2 patients received kidney from their child, one patient from their brother, one patient from their mother and one patient from their spouse. Only 15 patients $(6 \%)$ died within five years of which 10 patients were male and five were female. The mean age of transplant donors was $31.40 \pm 9.21$ years with a minimum age of 9 years and a maximum of 64 years. Most transplant recipients had blood group $\mathrm{A}+(35.2 \%)$, then $24.4 \%$ had O+ blood group (24.4\%; Table 1).

Regarding the turn of transplantation, 241 patients (96.4\%) were transplanted for the first time, 8 (3.2\%) patients were transplanted for the second time and only one patient $(0.4 \%)$ was transplanted for the third time. About 69 patients (27.6\%) received anti-thymocyte globulin (ATG) and ganciclovir before surgery, 22 patients $(8.8 \%)$ received ATG and valganciclovir and 24 patients (9.6\%) received ATG only (Table 2 ).

Symptomatic lymphocele occurred in patients receiving their first transplant. All patients were treated with percutaneous drainage procedure. Increased creatinine was found in three cases $(60 \%)$, lower extremity edema in 3 cases $(60 \%)$ and abdominal and pelvic pain in 4 cases $(80 \%)$ of patients. Asymptomatic lymphocele could not be evaluated due to lack of specific symptoms and lack of referral of patients. In total, transplant recipients were observed in only five patients with symptomatic lymphocele. There were three female patients and two male patients. The mean age of these patients was $40.2 \pm 17.2$ years with a minimum of 20 years and a maximum of 61 years, which occurred on average $48.4 \pm 21.12$ days after

Table 1. Blood group of transplant recipients

\begin{tabular}{llll}
\hline Variable & & Frequency & Percent \\
\hline \multirow{5}{*}{ Blood group } & $\mathrm{A}+$ & 88 & 35.2 \\
& $\mathrm{~B}+$ & 42 & 16.8 \\
& $\mathrm{O}+$ & 61 & 24.4 \\
& $\mathrm{AB}+$ & 24 & 9.6 \\
& $\mathrm{~A}-$ & 8 & 3.2 \\
& $\mathrm{~B}-$ & 10 & 4.0 \\
& O- & 13 & 5.2 \\
& AB- & 4 & 1.6 \\
& Total & 250 & 100 \\
\hline
\end{tabular}

Table 2. Frequency of turn of transplantation and drugs received before transplant recipients

\begin{tabular}{llcc}
\hline Variable & & No. & Percent \\
\hline \multirow{4}{*}{ Turn } & First & 241 & 96.4 \\
& Second & 8 & 3.2 \\
& Third & 1 & 0.4 \\
\hline \multirow{4}{*}{ Drug } & Anti-thymocyte globulin + valganciclovir & 22 & 8.8 \\
& Anti-thymocyte globulin + ganciclovir & 69 & 27.6 \\
\cline { 2 - 4 } & Anti-thymocyte globulin & 24 & 9.6 \\
\hline
\end{tabular}


surgery between 24 days and 78 days. Two live donors were used for two patients and a brain death donor was used for two patients. Three of these patients had $\mathrm{A}+$ blood group, one was $\mathrm{O}+$ and one was A- (Table 3 ).

\section{Discussion}

In a study by Joosten et al (24), the prognosis of lymphocele after kidney transplant surgery was evaluated. In this study, between January 2010 and December 2017, 1003 patients received a kidney transplant and 45 patients developed symptomatic lymphocele. The overall incidence of symptomatic lymphocele in this study group was $4.5 \%$ (95\% CI 3.6-5.8\%). The annual incidence varies between $1 \%$ and $11 \%$. Symptomatic lymphoceles were diagnosed after an average of 50 days after surgery (range 114-24 days). In our study, in a total of 5 years (May 2015 to August 2020), about 250 patients with ESRD underwent kidney transplant surgery. In total, transplant recipients were observed in only 5 patients (2\%) with symptomatic lymphocele confirmed by ultrasound, which was $2 \%$ less common than this study. On average, $48.4 \pm 21.12$ days occurred between 24 days and 78 days after surgery, which is close to this study. Patients in the symptomatic lymphocele group were older than the control group $(\mathrm{P}=$ 0.017 ), more patients had peritoneal dialysis catheter at the time of catheter transplantation ( $22 \%$ versus $18 \%, \mathrm{P}=0.007$ ) and most patients were present in the symptomatic lymphocele group with a diagnosis of autosomal dominant polycystic kidney disease ( $31 \%$ versus $16 \%, \mathrm{P}=0.001$ ). In our study, the mean age of subjects was $55.59 \pm 9.57$ years with the highest age of 84 years and the lowest age of 42 years. The mean age of women was $53.95 \pm 7.77$ years with the highest age of 69 years and the lowest age was 42 years and the mean age of males was $60.71 \pm 13.26$ years with the highest age of 84 years and the minimum age of 44 years. The mean age of our patients (60 years) is close to the symptomatic lymphocele group (56 years) in this study.

In a study by Zargar-Shoshtari et al (25), 2,147 kidney transplants were performed from living donors. In this study, symptomatic lymphoceles were observed in 17 kidney recipients $(0.08 \%$; $95 \%$ confidence interval, $0.04 \%$ to $1.2 \%)$. These episodes occurred between 10 and 90 days after transplantation (average; 6 weeks). Patients included 8 men and 9 women aged 24 to 53 years at the time of transplantation. One patient received his second allograft kidney. The clinical manifestations of lymphocele were variable after transplantation accompanied by increased serum creatinine level in 8 patients $(47.1 \%)$, abdominal pain and edema in five patients (29.4\%) and lower extremity inflammation in four patients $(23.5 \%)$. The diagnosis of lymphocele was confirmed by sonography and scintigraphy of the kidney. CT scan was performed in two complicated cases. In our study, in a total of 5 years, about 250 patients with ESRD underwent kidney transplant surgery. In total, lymphoceles were observed in only five patients $(2 \%)$, of which three were female and
Table 3. Frequency of lymphocele in transplanted kidney type and frequency of blood group in patients with symptomatic lymphocele

\begin{tabular}{llcc}
\hline Variable & & Frequency & Percent \\
\hline Current status & Living & 3 & 60.0 \\
of the patient & Deceased & 2 & 40.0 \\
\multirow{3}{*}{ Blood group } & A+ & 3 & 60.0 \\
& B+ & 1 & 20.0 \\
& O+ & 1 & 20.0 \\
\hline
\end{tabular}

two were male, which was confirmed by ultrasound and three patients $(60 \%)$ had creatinine increase, three patients (60\%) had lower extremity edema and four patients (80\%) had abdominal and pelvic pain. On average, $48.4 \pm 21.12$ days occurred between 24 days and 78 days after surgery.

In the study of Zargar-Shoshtari et al (25), percutaneous drainage was used to treat lymphocele in 11 patients, and povidone-iodine injection was performed for six of them. Lymph accumulation occurred in seven of 11 patients (63.6\%) who underwent skin drainage surgery. Three of these patients received povidone-iodine injections. These cases were successfully treated with open surgery. In the remaining six patients, the main method of intraperitoneal evacuation was surgery due to accumulation in several areas or inadequate access to percutaneous drainage. With an average follow-up of 14 months, no transplant loss or other complications were observed in these patients. In our report, all of these patients underwent skin drainage surgery. Povidone-iodine was not injected into any of the patients and no recurrence was observed (25). In our study, six patients $(2.4 \%)$ received transplant rejection. The mean age of these patients was $30.17 \pm 4.62$ years with a minimum age of 23 and a maximum age of 36 years. Additionally, four patients were male $(66.7 \%)$ and two patients were female (33.3\%). Living donor was used for three patients (50\%) and brain death /deceased donor was used for 3 patients (50\%). None of the recipients had a family relationship with the donor. ATG+ valganciclovir was injected for three patients $(50 \%)$ and ATG+ ganciclovir was injected for one patient (16.7\%) and no drug was injected for two patients (33.3\%). All six patients were alive and it was their first transplant. Asymptomatic lymphocele could not be evaluated due to lack of specific symptoms and lack of referral of patients.

Additionally, due to the low number of symptomatic lymphocele, no significant relationship was found between the incidence of symptomatic lymphocele and age, gender, multiple transplants and blood group (both recipient and donor); however, by comparing the lymphocele prevalence statistics in this study and previous studies in this field, the lower prevalence of lymphocele in Iranian studies compared to foreign studies can be inferred, which could be due to the higher number of live kidney donors (living donor) in Iran compared to other regions, also more accurate closure of lymphatic vessels, both when removing the transplanted kidney from the donor, and during the transplantation of the kidney for the recipient and using 
techniques other than cauterization for this purpose.

\section{Conclusion}

In the present study, it was found that the prevalence of symptomatic lymphocele in transplant recipients in the academic transplant center of Imam Reza hospital in Tabriz for 5 years was 5 patients (2\%) out of 250 patients with an average annual incidence of $1-2 \%$.

\section{Limitations of the study}

Generally, the sample size was small. However, further studies with larger sample size are needed to investigate the reason for lymphocele.

\section{Authors' contribution}

$A Z, F S M$ and MMR conducted the research. MMR and FSM collected the data. FSM and AZ analyzed the data. MMR prepared the primary draft. All authors edited the final draft and signed the manuscript.

\section{Conflicts of interest}

None.

\section{Ethical issues}

The research followed the tenets of the Declaration of Helsinki. The research was approved by the ethical committee of Tabriz University of Medical Sciences (\#IR.TBZMED.REC.1398.1048). This study was extracted from the medical thesis of Farnood Salmani Milani (Thesis \#62607). Accordingly, written informed consent was taken from all participants before any intervention. Moreover, ethical issues (including plagiarism, data fabrication, double publication) have been completely observed by theauthors.

\section{Funding/Support}

The authors would like to thank vice chancelleor of research deputy of Tabriz University of Medical Science for supporting this research (Grant\# 62607).

\section{References}

1. Mundy AR, Podesta ML, Bewick M, Rudge CJ, Ellis FG. The urological complications of 1000 renal transplants. Br J Urol. 1981;53:397-402. doi: 10.1111/j.1464-410x.1981.tb03216.x.

2. Dubeaux VT, Oliveira RM, Moura VJ, Pereira JM, Henriques FP. Assessment of lymphocele incidence following 450 renal transplantations. International Braz J Urol. 2004;30:18-21.

3. Metcalf KS, Peel KR. Lymphocele. Ann R Coll Surg Engl. 1993;75:387-92.

4. Atray NK, Moore F, Zaman F, Caldito G, Abreo K, Maley W, et alPost transplant lymphocele: a single centre experience. Clin Transplant. 2004;18 Suppl 12:46-9. doi: 10.1111/j.1399-0012.2004.00217.x.

5. Lopau K, Syamken K, Rubenwolf P, Riedmiller H, Wanner C. Impact of mycophenolate mofetil on wound complications and lymphoceles after kidney transplantation. Kidney Blood Press Res. 2010;33:52-9. doi: 10.1159/000289573.

6. Sim A, Ng LG, Cheng C. Occurrence of a lymphocele following renal transplantation. Singapore Med J. 2013;54:259-62. doi: 10.11622/smedj.2013104.

7. Starzl TE, Groth CG, Putnam CW, Penn I, Halgrimson CG, Flatmark A, et al. Urological complications in 216 human recipients of renal transplants. Ann Surg. 1970;172:1-22.

8. Markić D, Valencić M, Maricić A, Oguić R, Sotosek S, Spanjol J, et al. Limfocele i transplantacija bubrega [Lymphocele and renal transplantation]. Acta Med Croatica. 2011;65(4):305-9.
9. Nghiem DD, Beckman I. Intraperitoneal catheter drainage of lymphocele: an outpatient procedure. Transpl Int. 2005;18:721-3. doi: 10.1111/j.1432-2277.2005.00137.x.

10. Park SB, Kim JK, Cho KS. Complications of renal transplantation: ultrasonographic evaluation. J Ultrasound Med. 2007;26:615-33. doi: 10.7863/jum.2007.26.5.615.

11. Tasar M, Gulec B, Saglam M, Yavuz I, Bozlar U, Ugurel S. Posttransplant symptomatic lymphocele treatment with percutaneous drainage and ethanol sclerosis: long-term follow-up. Clin Imaging. 2005;29:109-16. doi: 10.1016/j. clinimag.2004.04.028.

12. Zagdoun E, Ficheux M, Lobbedez T, Chatelet V, Thuillier-Lecouf A, Bensadoun $\mathrm{H}$, et al. Complicated lymphoceles after kidney transplantation. Transplant Proc. 2010;42:4322-5. doi: 10.1016/j. transproceed.2010.09.127.

13. Goel M, Flechner SM, Zhou L, Mastroianni B, Savas K, Derweesh $\mathrm{I}$, et al. The influence of various maintenance immunosuppressive drugs on lymphocele formation and treatment after kidney transplantation. J Urol. 2004;171:1788-92. doi: 10.1097/01. ju.0000121441.76094.6f.

14. Naselli A, Andreatta R, Introini C, Fontana V, Puppo P. Predictors of symptomatic lymphocele after lymph node excision and radical prostatectomy. Urology. 2010;75:630-5. doi: 10.1016/j. urology.2009.03.011.

15. Sengupta P, Biswas S, Sen S, Chowdhury S. Unusual presentation post renal transplant lymphocele. J Assoc Physicians India. 2014;62:744-7

16. Khan MS, Ahmed S, Challacombe B, Goldsmith D, Steward M. Post-transplant lymphoproliferative disorder (PTLD) presenting as painful lymphocele 12 years after a cadaveric renal transplant. Int Urol Nephrol. 2008;40:547-50. doi: 10.1007/s11255-008-9367-2.

17. Bischof G, Rockenschaub S, Berlakovich G, Längle F, Mühlbacher F, Függer R, et al. Management of lymphoceles after kidney transplantation. Transplant Int. 1998;11:277-80.

18. Ishitani MB, DeAngelis GA, Sistrom CL, Rodgers BM, Pruett TL. Laparoscopic ultrasound-guided drainage of lymphoceles following renal transplantation. J Laparoendosc Surg. 1994;4:61-4. doi: 10.1089/lps.1994.4.61.

19. Ebadzadeh MR, Tavakkoli M. Lymphocele after kidney transplantation: where are we standing now? Urol J. 2008;5:144-8.

20. Senthil R, Bhattacharya A, Sharma A, Balasubramanian Harisankar $\mathrm{CN}$, Mittal BR. Delayed uptake of Tc-99m ethylene dicysteine in a post-transplant lymphocele demonstrated on dynamic renal scintigraphy and SPECT/CT. Clin Nucl Med. 2011;36:370-2. doi: 10.1097/RLU.0b013e31820aa1db.

21. Lucewicz A, Wong G, Lam VW, Hawthorne WJ, Allen R, Craig JC, Pleass HC. Management of primary symptomatic lymphocele after kidney transplantation: a systematic review. Transplantation. 2011 Sep 27;92:663-73. doi: 10.1097/TP.0b013e31822a40ef.

22. Ranghino A, Segoloni GP, Lasaponara F, Biancone L. Lymphatic disorders after renal transplantation: new insights for an old complication. Clin Kidney J. 2015;8:615-22. doi: 10.1093/ckj/ sfv064.

23. Melvin WS, Bumgardner GL, Davies EA, Elkhammas EA, Henry $\mathrm{ML}$, Ferguson RM. The laparoscopic management of post-transplant lymphocele. Surg Endosc. 1997;11:245-8.

24. Joosten M, d'Ancona FC, van der Meijden WA, Poyck PP. Predictors of symptomatic lymphocele after kidney transplantation. Int Urol Nephrol. 2019;51:2161-2167. doi: 10.1007/s11255-019-022690 .

25. Zargar-Shoshtari MA, Soleimani M, Salimi H, Mehravaran K. Symptomatic lymphocele after kidney transplantation: a singlecenter experience. Urol J. 2008;5:34-6. 